\title{
Research on Competence Evaluation Model of staffs of Petroleum Enterprises
}

\author{
Shen Xiao, Li Shigui, Wan Xi \\ Chongqing University of Science and Technology, Chongqing 401331, China

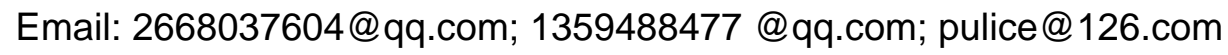

\begin{abstract}
Keywords: Petroleum enterprise; Shale gas; Primary Administrative Staffs; Competency; Evaluation index; Evaluation model
\end{abstract}

\begin{abstract}
This paper conducts an empirical research on the administrative staffs' competence characteristics of Shale Gas production enterprises. It selects five indexes, each of which is endowed with quotient, as the key competence characteristics, proposes evaluation methods, develops the evaluation model of primary administrative staffs of Shale Gas production enterprises and points out the specific application direction of the model.

The primary administrative staffs of shale gas production enterprise are the backbone of the implementation of shale gas production and the radical source of business efficiency. The quality of primary administrative staffs of production is the basis of their performance to exert. If the staff's quality does not match his or her post, it will result in bad exertion on performance, and thereby affecting the overall performance of the enterprise. To avoid this phenomenon, we must strictly implement the principle of the matching between competence and positions. The research on the model of primary administrative staffs of shale gas production enterprises to see whether they can be competent for the job or not, can, to a large extent, improve the efficiency of personnel selection, evaluation and appointment. Meanwhile, it can also provide reference for petroleum colleges to train oil talents. Based on this, the author of this paper ultimately gets the model for evaluation on primary administrative staffs' competence characteristics to see whether they can be competent for the job or not.
\end{abstract}

\section{Research Background}

The concept of competency characteristics was proposed by the famous American scholar McClelland in 1973. The research on competency of oil companies' staff have been gradually risen in recent years. Wang Miaoyun 、 Xiao Renbin、Fang Yan and Yang Ruijuan proposed to improve the primary staff's competency of oil companies.

In this research, the primary administrative staffs of shale gas enterprises refer to the primary cadres of production who are engaged in management of production. The sample includes 121 male primary cadres aged between 21 to 36 years old (with average age about 25 years old), with educational background of college or undergraduate. In practice, 118 people have filled in the questionnaires, with 110 copies returned and 100 copies valid and the effective rate $84.75 \%$. All the data have been processed and analyzed by SPSS (version 13.0) statistical software. The principal methods of research consist of Job Analysis Method, BEI (Behavioral Event Interview), questionnaire, Delphi Method, and Correlation Assessment Method. One of shale gas drilling companies subordinated to an oilfield has been selected as the target experimental enterprise with two years research period.

\section{The Construction of Competence Model of Administrative Staffs of Shale Gas Production Enterprises}

2.1 Identifying Competence Characteristics Norm

2.1.1 Preliminarily selected indexes

First of all, the post responsibility of front-line administrative staffs (drilling team leader, 
technicians)in Shale Gas corporations and the previous year's performance evaluation materials of some Shale Gas enterprises need to be collected and then excellent and general samples in performance evaluation are found out by analysizing and sampling the annual evaluation results. Meanwhile, interview about the critical events through behavioral event interview approach is conducted to get the data on the model of the front-line administrative staffs' competence characteristics in Shale Gas enterprises. The gained data is further coded to find out the forty indexes of possible competence characteristics through descriptive analysis of thematic mode analysis, which can be divided into three categories as basic quality, administrative ability and vocational ethics based on their different effects on performance. By integrating those characteristics, the questionnaire (including 40 items) on the competence characteristics of front-line administrative staffs in Shale Gas enterprises is designed. Then we need to deliver and collect the questionnaires and make statistics of them through SPSS software to find out the rank and degree of significance of the possible competence characteristics. Here we have initially gained in total 24 competence characteristics indexes of front-line administrative staffs in petroleum enterprises by refering the relevant paper materials and the approach of content analysis. After coding the characteristics into a Likert 5 points chart, we invite 12 experts in this field including 5 advanced engineers, 4 experienced professors from the Universities of Petroleum as well as 3 senior administrative staffs from the petroleum enterprises to evaluate the degree of the significance of these characteristics from Not Important At All (1 score) to Extremely Important (5 Score) using Delphi method. According to the difference in degree of importance, twelve competence characteristics indexes have been selected by counting out the norms below 4 score(very important) and are recoded as $\omega_{1} \sim \omega_{2}$. (See Table 1)

Table 1: Average Score of Degree of Importance of Competence Characteristics

\begin{tabular}{|c|c|c|c|c|c|}
\hline \multicolumn{2}{|c|}{ Basic Qualities } & \multicolumn{2}{|c|}{ Administrative Ability } & \multicolumn{2}{|l|}{ Vocational Ethics } \\
\hline Indexes & Average scores & Indexes & Average scores & Indexes & Average scores \\
\hline$\underline{\text { Planning Ability } \omega_{1}}$ & $\underline{4.83}$ & $\underline{\text { Leadership Ability } \omega_{5}}$ & $\underline{4.50}$ & Perception of Business Interests $\omega_{9}$ & $\underline{4.75}$ \\
\hline Credibility $\omega_{2}$ & $\underline{4.50}$ & Communication Ability $\omega_{6}$ & $\underline{4.58}$ & Incorruptibility, self-descipline $\omega_{10}$ & $\underline{4.83}$ \\
\hline Teamwork $\omega_{3}$ & $\underline{4.67}$ & Negotiation Ability $\omega_{7}$ & $\underline{4.50}$ & $\underline{\text { Responsibility } \omega_{11}}$ & $\underline{4.75}$ \\
\hline Physical Quality $\omega_{4}$ & $\underline{4.50}$ & $\underline{\text { Organization Ability } \omega_{8}}$ & $\underline{4.67}$ & Pressure Resistance $\omega_{12}$ & $\underline{4.58}$ \\
\hline Sense of Team Honor & 3.25 & Interpersonal Ability & 2.83 & Deciding Ability & 3.08 \\
\hline Self-confidence & 2.58 & Memory and Observation & 3.17 & Strict Style & 2.25 \\
\hline Loyalty & 3.08 & Self-adjustment & 2.08 & Innovation & 2.08 \\
\hline Principle & 3.42 & Failure Resistance & 2.08 & Width of Knowledge & 2.50 \\
\hline
\end{tabular}

* Underlined parts are the selected indexes

2. 1. 2 Ultimately selected indexes

The above 12 indexes needs further selection. There are two methods of selection: first, SPSS software is applied to discover and analysis data based on experts' questionnaire; second, a study can be done with gray relevance approach and a matrix can be established through counting gray relevance thus identifying the ultimate indexes by advantage analysis principle.

The enterprise in the experiments has 30 front-line administrative staffs including 8 newcomers in March, 2011. In the preliminary period, we evaluate them by scoring their competence characteristics indexes and the results of their score $\left(\omega_{i}\right)$ of all the indexes and the next two years' task performance $\mu_{1}$ and contextual performance $\mu_{2}$ are shown in table 2 . 
Table 2: Norm Value and Performance Data of Front-line Management Staff in Petroleum Corp.

\begin{tabular}{|c|c|c|c|c|c|c|c|c|c|c|c|c|c|c|}
\hline \multirow{3}{*}{ Members } & \multicolumn{10}{|c|}{ Competence characteristics indexex } & \multicolumn{1}{|c|}{ Performance } \\
\cline { 2 - 16 } & $\omega_{1}$ & $\omega_{2}$ & $\omega_{3}$ & $\omega_{4}$ & $\omega_{\mathbf{5}}$ & $\omega_{\mathbf{6}}$ & $\omega_{7}$ & $\omega_{\mathbf{8}}$ & $\omega_{9}$ & $\omega_{10}$ & $\omega_{11}$ & $\omega_{12}$ & $\mu_{1}$ & $\mu_{2}$ \\
\hline 1 & 90 & 80 & 90 & 80 & 80 & 90 & 75 & 80 & 80 & 80 & 90 & 0 & 76 & 70 \\
\hline 2 & 80 & 80 & 80 & 80 & 80 & 60 & 80 & 80 & 80 & 80 & 75 & 70 & 59 & 78 \\
\hline 3 & 80 & 80 & 50 & 70 & 80 & 85 & 40 & 60 & 70 & 75 & 75 & 80 & 76 & 76 \\
\hline 4 & 85 & 70 & 50 & 80 & 85 & 80 & 50 & 60 & 85 & 80 & 70 & 0 & 77 & 79 \\
\hline 5 & 86 & 76 & 50 & 80 & 90 & 80 & 50 & 70 & 85 & 80 & 80 & 0 & 76 & 80 \\
\hline 6 & 80 & 80 & 50 & 50 & 70 & 70 & 40 & 65 & 70 & 55 & 80 & 70 & 89 & 80 \\
\hline 7 & 70 & 90 & 80 & 80 & 80 & 80 & 70 & 80 & 80 & 80 & 70 & 75 & 90 & 81 \\
\hline 8 & 60 & 60 & 60 & 50 & 70 & 60 & 60 & 60 & 50 & 50 & 70 & 0 & 65 & 70 \\
\hline
\end{tabular}

We consider $\mu_{i}$ (i=l, 2)as reference sequence while $\omega_{i}$ (i= $1,2, \ldots, 12$ )as comparative sequence.Detailed analysis process is shown as follows:

(1) Establishing Factor Space

$y_{i}=\left[\begin{array}{ll}1.000 & 0.912 \\ 0.776 & 1.016 \\ 1.000 & 0.990 \\ 1.013 & 1.029 \\ 1.000 & 1.042 \\ 1.171 & 1.042 \\ 1.184 & 1.055 \\ 0.855 & 0.912\end{array}\right] x_{j}=\left[\begin{array}{llllllllllll}1.141 & 1.039 & 1.412 & 1.123 & 1.008 & 1.190 & 1.290 & 1.153 & 1.067 & 1.103 & 1.180 & 0.000 \\ 1.014 & 1.039 & 1.255 & 1.123 & 1.008 & 0.793 & 1.376 & 1.153 & 1.067 & 1.103 & 0.984 & 1.898 \\ 1.014 & 1.039 & 0.784 & 0.982 & 1.008 & 1.124 & 0.688 & 0.865 & 0.933 & 1.034 & 0.984 & 2.169 \\ 1.078 & 0.909 & 0.784 & 1.123 & 1.071 & 1.058 & 0.860 & 0.865 & 1.133 & 1.103 & 0.918 & 0.000 \\ 1.090 & 0.987 & 0.784 & 1.123 & 1.134 & 1.058 & 0.860 & 1.009 & 1.133 & 1.103 & 1.049 & 0.000 \\ 1.014 & 1.039 & 0.784 & 0.702 & 0.882 & 0.926 & 0.688 & 0.937 & 0.933 & 0.759 & 1.049 & 1.898 \\ 0.887 & 1.169 & 1.255 & 1.123 & 1.008 & 1.058 & 1.204 & 1.153 & 1.067 & 1.103 & 0.918 & 2.034 \\ 0.761 & 0.779 & 0.941 & 0.702 & 0.882 & 0.793 & 1.032 & 0.865 & 0.667 & 0.690 & 0.918 & 0.000\end{array}\right]$

(2) Calculating with the following formula (1) \& (2)

$$
\begin{aligned}
& \gamma\left(y_{i}(k), x_{j}(k)\right)=\frac{\min _{i} \min _{j} \min _{k}\left|y_{i}(k)-x_{j}(k)\right|+\xi \max _{i} \max _{j} \max _{k}\left|y_{i}(k)-x_{j}(k)\right|}{\left|y_{i}(k)-x_{j}(k)\right|+\xi \max _{i} \max _{j} \max _{k}\left|y_{i}(k)-x_{j}(k)\right|} \\
& \gamma\left(y_{i}, x_{j}\right)=\frac{1}{n} \sum_{k=1}^{n} \gamma\left(y_{i}(k) \cdot x_{j}(k)\right)
\end{aligned}
$$

(3) Gaining the gray relevance matrix

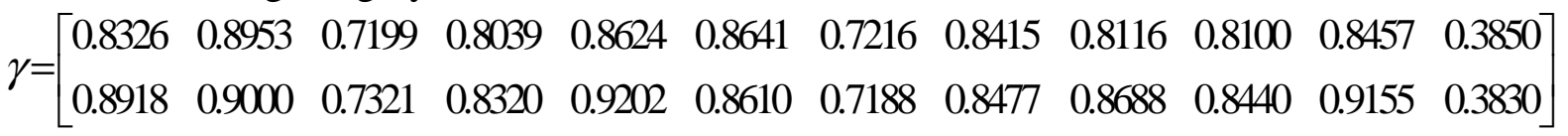

The matrix is expressed in the following form for better understanding (See Table 3):

\begin{tabular}{|l|c|c|c|c|c|c|c|c|c|c|c|c|c|}
\hline & & $r_{i}$ & $r_{i 2}$ & $r_{i 3}$ & $r_{i 4}$ & $r_{i 5}$ & $r_{i 6}$ & $r_{i}$ & $r_{i 8}$ & $r_{i 9}$ & $r_{i 10}$ & $r_{i 1}$ & $r_{i 2}$ \\
\hline $\begin{array}{l}\text { Task } \\
\text { Performance }\end{array}$ & $\gamma_{1 j}$ & 0.8326 & 0.8953 & 0.7199 & 0.8039 & 0.8624 & 0.8641 & 0.7216 & 0.8415 & 0.8116 & 0.8100 & 0.8457 & 0.3850 \\
\hline $\begin{array}{l}\text { Contextual } \\
\text { Performance }\end{array}$ & $\gamma_{2 j}$ & 0.8918 & 0.9000 & 0.7321 & 0.8320 & 0.9202 & 0.8610 & 0.7188 & 0.8477 & 0.8688 & 0.8440 & 0.9155 & 0.3830 \\
\hline Sum & $\sum_{i=1}^{2} \gamma_{0}$ & 1.7244 & 1.7953 & 1.452 & 1.6359 & 1.7826 & 1.7251 & 1.4404 & 1.6892 & 1.6804 & 1.654 & 1.7612 & 0.768 \\
\hline Rank & $:$ & 5 & 1 & 10 & 9 & 2 & 4 & 11 & 6 & 7 & 8 & 3 & 12 \\
\hline
\end{tabular}

Seen from the above matrix, the effects of variables as credibility, communication ability, leadership, responsibility and negotiation ability on task performance have more obvious advantages which respectively rank No. 1 to No. 5 while the variables as leadership, responsibility, credibility, plan ability and business interests perception have greater effects on contextual performance which respectively rank No. 1 to No. 5. As for the comprehensive performance, the effects of credibility, leadership, responsibility, communication ability and plan ability rank from No. 1 to No. 5 with their effective factor above 1.7 scores. Therefore, we ultimately set the five indexes as the key ones of competence characteristics which are coded again as $\omega_{1}^{*} \sim \omega_{5}^{*}$.

2.2 Identifying the Mathematical Model of Competency Characteristics Evaluation

2.2.1 Mathematical Model of Assessment 
we adopt the weighted scoring model. Experts are asked to score the key indexes of competency characteristics, which is followed by weighted calculation.

According to our competency characteristics index system, the evaluation model is constructed as follow:

$$
\bar{s}=\frac{1}{n} \sum_{i=1}^{n} \sum_{j=1}^{s} W_{j} * X_{i j}
$$

In the formula, $\bar{s}$ refers to the sum of mean weighted score, $n-$ means the number of experts, $W_{j}$-refers to the $\mathrm{j}$-th weighting of competency characteristics, $x_{i j}$-is the score of the $\mathrm{j}$-th competency characteristics from the i-th expert.

The scoring scale consists of 7 grades, namely, extremely excellent, excellent, good, moderate, poor, very poor and extremely poor, whose corresponding numerical intervals are 90-100, 80-90, 70-80, 60-70, 50-60, 40-50 and 0-40.

2.2.2 Identifying the Weighting of Indexes

sum up the score of grey correlation degree of the five indexes and that of integrated performance respectively. Then the relative importance of indexes, i.e. the relative weighting of indexes can be gained after the score of each index is divided by the sum, the specific weighting of competency indicators is as Table 4 shows.

Table 4: The Weighting Distribution of Key Competency Characteristics Indexes

\begin{tabular}{|c|c|c|c|c|c|}
\hline $\begin{array}{c}\text { Key competence } \\
\text { characteristics }\end{array}$ & $\begin{array}{c}\text { Credibility } \\
\omega_{1}^{*}\end{array}$ & $\begin{array}{c}\text { Leadership } \\
\text { ability } \omega_{2}^{*}\end{array}$ & $\begin{array}{c}\text { Responsibility } \\
\omega_{3}^{*}\end{array}$ & $\begin{array}{c}\text { Communication } \\
\text { ability } \omega_{4}^{*}\end{array}$ & $\begin{array}{c}\text { Planning } \\
\text { ability } \omega_{5}^{*}\end{array}$ \\
\hline Weighting $W_{j}$ & 0.2042 & 0.2028 & 0.2004 & 0.1963 & 0.1963 \\
\hline
\end{tabular}

\section{The Application of Model Calculation}

Based on the competency characteristics evaluation model of front-line administrative staffs in shale gas production, 5 staffs, newcomers of petroleum enterprises in March, 2013, are evaluated and scored by 6 experts (signified as $\mathrm{Z}_{1}, \mathrm{Z}_{2}, \ldots \mathrm{Z}_{6}$ ). According to the calculation formula 3 , calculation mode $\bar{S}=\frac{1}{6} \sum_{i=1}^{6} \sum_{j=1}^{5} W_{j} * x_{i j}$ is gained, the statistics of experts' scoring of A can be seen in Table 5.

Table 5: Statistics of Experts' Scoring

\begin{tabular}{|c|c|c|c|c|c|c|c|}
\hline \multirow{2}{*}{ Number of competency } & \multirow{2}{*}{ Weighting $\quad\left(W_{j}\right)$} & \multicolumn{6}{|c|}{ Experts' scores $\left(x_{i j}\right)$} \\
\hline & & $\mathbf{Z}_{1}$ & $\mathbf{Z}_{2}$ & $\mathbf{Z}_{3}$ & $\mathbf{Z}_{4}$ & $\mathbf{Z}_{5}$ & $\mathbf{Z}_{6}$ \\
\hline$\omega_{1}^{*}$ & 0.2042 & 86 & 90 & 85 & 85 & 85 & 80 \\
\hline$\omega_{2}^{*}$ & 0. 2028 & 77 & 70 & 65 & 70 & 75 & 76 \\
\hline$\omega_{3}^{*}$ & 0. 2004 & 70 & 70 & 73 & 74 & 75 & 77 \\
\hline$\omega_{4}^{*}$ & 0.1963 & 66 & 70 & 66 & 64 & 68 & 69 \\
\hline$\omega_{5}^{*}$ & 0. 1963 & 63 & 66 & 66 & 68 & 69 & 69 \\
\hline \multicolumn{2}{|c|}{$\sum_{j=1} W_{j} * x_{i j}$} & 72.5275 & 73.2988 & 71.0798 & 72.2942 & 74.4901 & 74.2690 \\
\hline \multicolumn{2}{|c|}{$\bar{s}$} & \multicolumn{6}{|c|}{72.99323} \\
\hline
\end{tabular}

A’s final score is approximately 72.99, graded as “good”. Other staff can also be evaluated in the same way.

\section{The Practical Application of Competency Model}

The competency model of administrative staffs of shale gas enterprises, combined with existing human resource management models and practices, can be applied practically in the following four aspects: 
First, the human resource adminstrative system based on competency model can be built. The key lies in properly measuring the establishment of competency model of managerial staff of different levels and integrating each model of human resource administration organically into a complete management system.

Second, competency model can be applied in personnel allocation. People with different capabilities can be matched with proper posts by means of competency evaluation, which helps realize the perfect match both between person and post and between person and work.

Third, the application of competency model helps carry out competency training and career development. By competency evaluation, the strengths and weaknesses of each individual and the shortcoming of collective integration can be found, which, in turn, provides means for developing capacity-building plans, identifying the training focus and enhancing the integration ability of individual and collective by taking effective measures.

Fourth, in-depth collaboration of production and research can be achieved. Currently, the shortage of shale gas talents is one of the constraints to the shale gas industry. The study of competency can provide theoretical support for cultivating talents in this field at universities, clarify the quality structure of personnel training and finally serve the personnel needs of petroleum enterprises.

\section{References}

[1] MeClelland D. C. Testing for Competence Rather Than for Intelligence [J]. American Psychologist, 1973, (28).

[2] Peng Changgui \& Zhangjian. Progress in Study of Competence Characteristics and Its Evaluation [J. Administration of Science Research, 2006,27(6).

[3] Zhong Lifeng \& Shikan. New Progress in Study of Competence Characteristics [J]. Review on Nankai Management, 2003, (3).

[4] Chen Minke. The Analysis and Application of Post Based on Competence [J]. Research on Comparative Education, 2004, (3).

[5] Peng Jianfeng \& Rao Zheng. Human Resource Management Based on Competence [M]. Beijing: Publication of Renmin University of China, 2003.

[6] Wan Yu \& Yong Qidong. Research on Core Technicians' Competence Evaluation Model [J]. Value Engineer, 2007,26(9).

[7] Peng Jianfeng. Introduction to Human Resource Management [M]. Shanghai: Fudan University Publication, 2003.

[8] Jin Yanghua, Chen Weiqi \& Wang Chongming. Research on the relationship between Management Ability and Work Performance [J]. Psychological Science, 2004,27(6).

[9] Wang Miaoyun \& Xiao Renbin. Research on competence model of front-line staffs in Oil \& Gas Enterprises [J]. Oil and Chemical Technology Economy, 2006,22(1).

[10] Fang Yan. Model of Competence Comprehensive Evaluation of Middle Administrative Staffs in Oil and Chemistry Enterprises[J]. Management Information in China, 2008, 11(2).

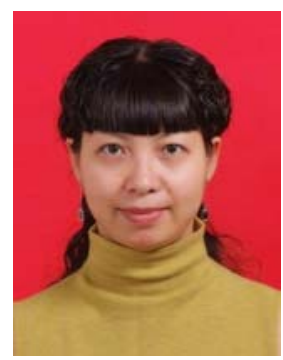

Shenxiao, female, was born in Shanghai in April, 1969. She is now an associate professor with master degree in Chongqing University of Science and Technology. Her main research interests include: ideological and political education, human resources management, etc.. 